\title{
Saflufenacil no controle de Luffa aegyptiana, Merremia cissoides, Mucuna aterrima e Ricinus communis ${ }^{1}$
}

\section{Saflufenacil in controlling Luffa aegyptiana, Merremia cissoides, Mucuna aterrima and Ricinus communis}

\author{
Patricia Andrea Monquero $^{2}$, Victor Dalla Costa ${ }^{3}$, Valquiria Krolikowski ${ }^{3}$
}

Resumo - O presente trabalho teve por objetivo avaliar a eficácia do herbicida saflufenacil no controle de plantas daninhas em pós-emergência. O herbicida saflufenacil foi aplicado sobre as plantas daninhas Luffa aegyptiana, Merremia cissoides, Mucuna aterrima e Ricinus communis, quando estas estavam com o segundo par de folhas verdadeiras nas doses de $0 \mathrm{x}, 0,25 \mathrm{x}, 0,5 \mathrm{x}, 1 \mathrm{x}$, $2 \mathrm{x}, 4 \mathrm{x}, 8 \mathrm{x}$ sendo $\mathrm{x}$ a dose comercial recomendada $\left(50 \mathrm{~g}\right.$ i.a. $\left.\mathrm{ha}^{-1}\right)$. A avaliação de controle e massa da matéria seca da parte aérea das plantas foi feita aos 28 dias após aplicação. O delineamento experimental utilizado foi o inteiramente casualizado com quatro repetições. A dose de $50 \mathrm{~g}$ i.a. $\mathrm{ha}^{-1}$ de saflufenacil controlou de maneira satisfatória $M$. cissoides, $M$. aterrima e $R$. communis. Entretanto, L. aegyptiana foi tolerante quando saflufenacil foi utilizado na dose comercial. Podese concluir que o herbicida saflufenacil foi efetivo no controle de M. cissoides, M. aterrima e $R$. communis mas não controlou L. aegyptiana quanto utilizado na dose de $50 \mathrm{~g}$ i.a. $\mathrm{ha}^{-1}$.

Palavras-Chave: planta daninha, sensibilidade, herbicida, controle químico, tolerância.

\begin{abstract}
The present study aimed to verify the effectiveness of saflufenacil herbicide in postemergence weeds control. Saflufenacil herbicide was applied over Luffa aegyptia, Merremia cissoides, Mucuna aterrima and Ricinus communis weeds, when the plants contained the second pair of true leaves at $0 \mathrm{x}, 0.25 \mathrm{x}, 0.5 \mathrm{x}, 1 \mathrm{x}, 2 \mathrm{x}, 4 \mathrm{x}, 8 \mathrm{x}$ with the last one the commercial recommended dose $\left(50 \mathrm{~g}\right.$ a.i. $\left.\mathrm{ha}^{-1}\right)$. The evaluations of control and plants canopy dry matter mass were conducted at 28 days after treatments application. The experimental design was entirely randomized with four replications. Saflufenacil dose of $50 \mathrm{~g}$ a.i. ha ${ }^{-1}$ controlled satisfactorily $M$. cissoides, M. aterrima and $R$. communis. However, L. aegyptiana specie was tolerant when the herbicide was used in the recommended dose. It was possible to conclude that saflufenacil herbicide was effective in controlling M. cissoides, M. aterrima and Ricinus communis but $L$. aegyptiana specie was tolerant when applied $50 \mathrm{~g}$ a.i. ha ${ }^{-1}$.
\end{abstract}

\footnotetext{
${ }^{1}$ Recebido para publicação em 22/06/2011 e na forma revisada em 10/11/2011.

${ }^{2}$ Professora Adjunta do Centro de Ciências Agrárias, Universidade Federal de São Carlos, Rodovia Anhanguera, km 174, Araras, SP. Email: pamonque@cca.ufscar.br

${ }^{3}$ Discentes de graduação do curso de Engenharia agronômica do Centro de Ciências Agrárias, Universidade Federal de São Carlos, Rodovia Anhanguera, km 174, Araras, SP. Emails: victordallacosta@ hotmail.com; valkrolikowski@hotmail.com
} 
Key-words: Weeds, sensitivity, herbicide, chemical control, tolerance.

\section{Introdução}

Apesar de a cana-de-açúcar ser altamente eficiente na utilização dos recursos disponíveis para o seu crescimento e de apresentar fisiologia do tipo $\mathrm{C}_{4}$, ela é muito afetada pela competição com as plantas daninhas, por apresentar, na maioria das situações, brotação e crescimento iniciais lentos (Procópio et al., 2003).

As plantas infestantes podem interferir no processo produtivo da cana-de-açúcar através da competição por recursos do meio, como água, luz e nutrientes, da liberação de substâncias alelopáticas, da atuação como hospedeiro de pragas e doenças comuns à cultura e da interferência nas práticas de colheita (Pitelli, 1985). A ocorrência de um ou mais desses componentes de interferência poderá causar reduções na quantidade da canade-açúcar colhida, além de diminuir o número de cortes economicamente viáveis (Lorenzi, 1988).

Em consequência dessa característica, é necessário manter a lavoura de cana-de-açúcar livre de plantas daninhas. Segundo Kuva et al. (2001) a cultura da cana-de-açúcar pode conviver com a comunidade infestante até 89 dias após o plantio (DAP), sem sofrer redução significativa na produtividade. $\mathrm{O}$ período mínimo de controle, para assegurar a máxima produtividade, foi de 138 DAP. Dessa forma, o controle das plantas daninhas foi crítico no período compreendido entre 89 e 138 DAP. Assim, uma das ferramentas mais utilizadas para o manejo das plantas daninhas consiste na aplicação de herbicidas.

$\mathrm{Na}$ colheita mecanizada sem queima, as folhas, bainhas, ponteiros, além de quantidade variável de pedaços de colmo, são cortados, triturados e lançados sobre a superfície do solo, formando a cobertura de palha. Segundo
Trivelin et al. (1996), essa quantidade de palha de canaviais colhidos sem queima varia de 10 a $30 \mathrm{t} \mathrm{ha}^{-1}$.

A cobertura morta ocasiona mudanças químicas, físicas e biológicas no solo e pode provocar seleção da comunidade infestante, suprimindo a infestação de plantas daninhas normalmente consideradas importantes nos canaviais. Destacam-se as espécies Digitaria horizontalis, Brachiaria plantaginea, Brachiaria decumbens e Panicum maximum (Velini et al., 2000; Medeiros, 2001; Gravena et al., 2004). No entanto, estão surgindo plantas-problema no sistema de cana-crua, como Euphorbia heterophylla, Ipomoea grandifolia (Martins et al., 1999; Monquero et al., 2008 e Monquero et al. 2011), Merremia (Correia \& Kronka, 2010) e Mucuna aterrima (Silva et al., 2010).

Uma possível alternativa para o controle dessas espécies problemáticas é o herbicida saflufenacil. Trata-se de uma molécula pertencente à família dos pirimidinedione, que inibe a enzima protoporfirinogênio oxidase (PROTOX). Em virtude de escassos conhecimentos sobre a ação deste herbicida no controle de algumas plantas daninhas, o presente trabalho teve como objetivo, avaliar a sensibilidade de Luffa aegyptiana, Merremia cissoides, Mucuna aterrima e Ricinus communis ao saflufenacil.

\section{Material e métodos}

O trabalho foi realizado em casa-devegetação do Centro de Ciências Agrárias da Universidade Federal de São Carlos, Araras/SP. As sementes das espécies Luffa aegyptiana, Merremia cissoides, Mucuna aterrima e Ricinus communis foram adquiridas da empresa AgroCosmos. As unidades experimentais foram representadas por vasos 
plásticos com capacidade para $1 \mathrm{dm}^{-3}$, preenchidos com solo classificado como Latossolo Vermelho Distrófico. Aos dez dias após a emergência das plântulas, foi realizado desbaste, mantendo-se três plantas por unidade.

$\mathrm{O}$ herbicida saflufenacil $\left(\mathrm{Heat}^{\circledR}\right)$ foi aplicado sobre as plantas daninhas, quando estas estavam com o segundo par de folhas verdadeiras completamente desenvolvidas, nas doses de 0x (testemunha), 0,25x, 0,5x, 1x, 2x, $4 \mathrm{x}$ e $8 \mathrm{x}$, sendo $\mathrm{x}$ a dose comercial recomendada (50 g i.a. ha ${ }^{-1}$ ). Para aplicação utilizou-se um pulverizador costal pressurizado por $\mathrm{CO}_{2}$, munido de pontas XR 110.02, pressão de 2,0

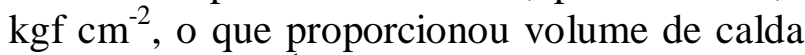
de $200 \mathrm{~L} \mathrm{ha}^{-1}$. A irrigação das plantas aspergidas foi retomada um dia após a aplicação. No preparo das soluções foi adicionado o adjuvante Dash a 0,5\% (v/v).

A avaliação de controle das plantas foi realizada visualmente, aos 28 dias após aplicação dos tratamentos (DAT), utilizando-se escala percentual, em que zero (0) e cem (100) corresponderam à ausência de injúria e morte total das plantas, respectivamente (ALAM, 1974). Aos 28 DAT, também foi determinada a massa da matéria seca da parte aérea das plantas, coletando-as rente ao solo e acondicionando-as para secar em estufa com circulação forçada de ar a $65^{\circ} \mathrm{C}$, até massa constante, sendo em seguida determinada a matéria seca por planta (Benincasa, 2003).

$\mathrm{O}$ delineamento experimental utilizado para cada espécie foi o inteiramente casualizado, com quatro repetições. Os dados obtidos foram analisados quanto à normalidade e homogeneidade e, posteriormente, submetidos à análise da variância $(\mathrm{p} \leq 0,05)$; quando significativos, foi realizada a análise de regressão.

\section{Resultados e discussão}

Mucuna aterrima foi controlada de maneira eficiente utilizando-se saflufenacil a partir de 21,0 g i.a. ha ${ }^{-1}$ (>80\%). Entretanto, o uso da dose comercial do produto, por sua vez, proporcionou controle de 98,38\% (Figura 1). Ressalta-se, que o produto foi utilizado em pósemergência inicial, ou seja, com plantas $M$. aterrima apresentando o segundo par de folhas verdadeiras.

Em relação à massa da matéria seca da parte aérea das plantas de mucuna, o tratamento com $12,5 \mathrm{~g}$ i.a ha ${ }^{-1}$ de saflufenacil reduziu a produção em $66,99 \%$ quando comparada com a testemunha, sendo que esta redução foi diretamente proporcional ao aumento da dose do produto (Figura 1). A mucuna-preta tornou-se uma planta daninha problemática em algumas áreas de cana-deaçúcar do Estado de São Paulo. Trata-se de uma espécie anual, da família Fabaceae, pouco exigente quanto à fertilidade do solo, utilizada em consórcios com milho, sorgo e milheto e como adubo verde (Burle et al., 2006). Nas áreas de renovação do canavial a mucuna-preta é empregada em rotação com a cana-de-açúcar para adubação verde. Se as sementes produzidas pelas plantas não forem colhidas e, simplesmente, incorporadas junto com os demais resíduos vegetais ao solo, há o aumento do banco de sementes dessa espécie no solo, cujas sementes apresentam dormência e, portanto, distribuem a germinação ao longo do tempo. O controle de $M$. aterrima, $M$. cinerea e $M$. deeringiana também pode ser feito com o uso dos herbicidas ametryn+trifloxysulfuronsodium e 2,4 D (Silva et al., 2010).

A espécie $R$. communis foi satisfatoriamente controlada pelo saflufenacil em doses a partir de $20 \mathrm{~g}$ i.a. ha $^{-1}$. Resultados semelhantes foram constatados para massa da matéria seca da parte aérea das plantas daninhas, cuja redução ocorreu já na menor dose utilizada (Figura 2). Em áreas com cana colhida mecanicamente, a adição de palha de cana-de-açúcar ao solo não altera a emergência e interfere positivamente no desenvolvimento inicial da mamona (Novo et al., 2007). Portanto, pode ocorrer aumento na infestação 
por esta espécie de planta daninha ao longo do tempo. O herbicida trifloxysulfuron-sodium, na dose de $50 \mathrm{~g}$ i.a. ha ${ }^{-1}$, é fitotóxico para a cultura da mamona (Queiroz, 2007).
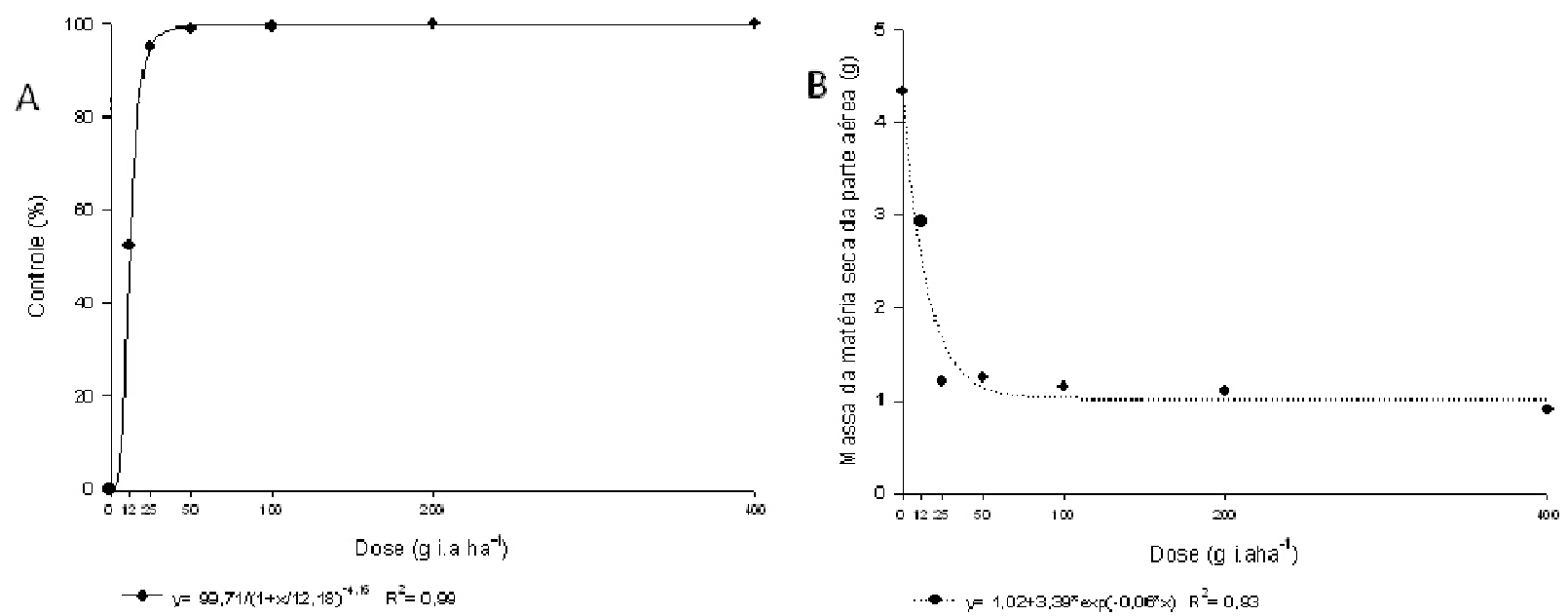

Figura 1. Porcentagem de controle (A) e massa de matéria seca da parte aérea de Mucuna aterrima (B) aos 28 dias após aplicação do herbicida saflufenacil.
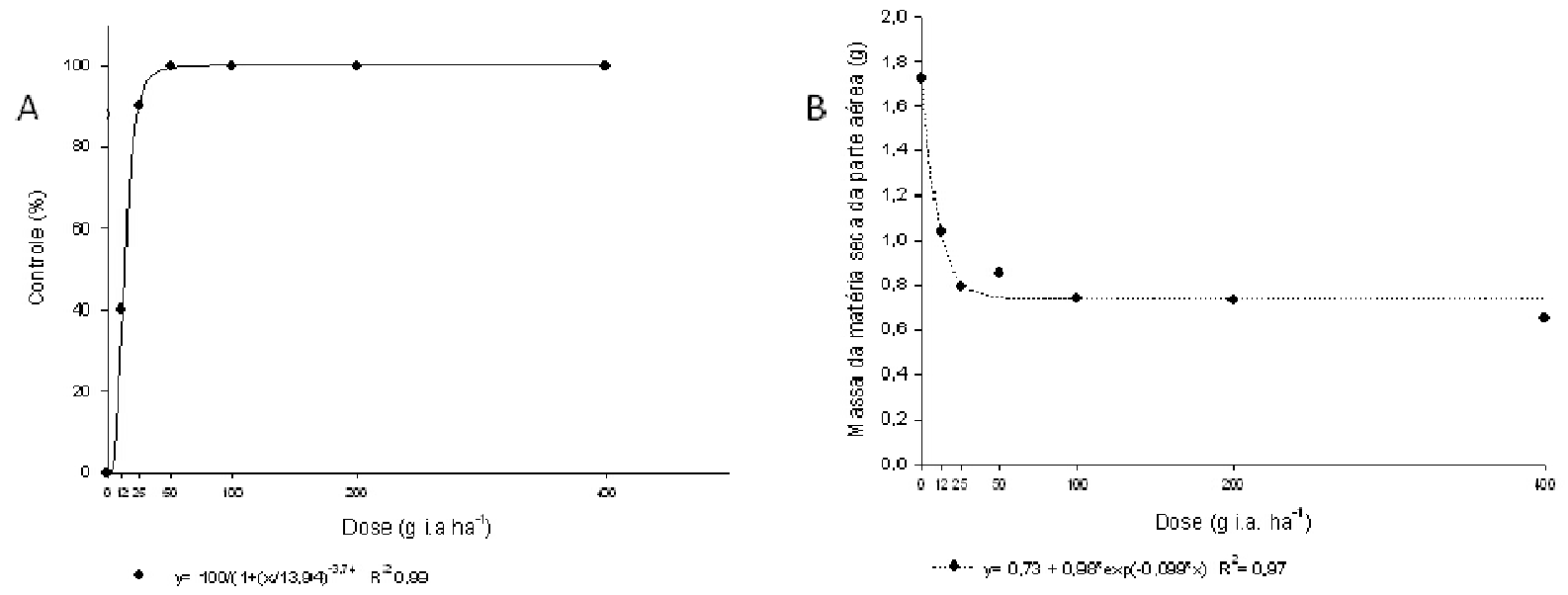

Figura 2. Porcentagem de controle (A) e massa de matéria seca da parte aérea de Ricinus communis (B) aos 28 dias após aplicação do herbicida saflufenacil.

O controle de $M$. cissoides também foi efetivo a partir de $16,90 \mathrm{~g}$ i.a. ha ${ }^{-1}$, tendo a matéria seca da parte aérea sido reduzida em $50 \%$, na menor dose do herbicida (Figura 3). Cerca de $74 \%$ das espécies dos géneros Ipomoea e Merremia da região Sudeste do Brasil são trepadeiras, apresentando caules e ramos volúveis. Elas se entrelaçam em plantas vizinhas ou crescem sobre obstáculos
(Kissmann \& Groth, 1999). Além dos prejuízos ocasionados pela competição por água, luz, nutrientes e espaço, essas espécies causam sérios danos à cana-de-açúcar no momento da colheita, pois dificultam o corte mecanizado, o que compromete o rendimento das máquinas e a qualidade do produto colhido (Correia \& Kronka, 2010). O controle de M. cissoides em áreas cultivadas com cana-de-açúcar pode ser 
realizado com alguns herbicidas como a mistura em tanque de [trifloxysulfuromsodium+ ametrina + [diuron+ hexazinone], metribuzin isolado ou em mistura com trifloxysulfurom-sodium + ametrina (Correia \& Kronka, 2010), assim como com o saflufenacil.

A espécie L. aegyptiana se mostrou mais tolerante ao herbicida saflufenacil, sendo que a dose recomendada (50 g i.a ha $\left.{ }^{-1}\right)$ apenas proporcionou controle insatisfatório (64\%), A partir de $100 \mathrm{~g}$ i.a. ha ${ }^{-1}$, a espécie foi controlada em $80 \%$ (Figura 4), mas ainda assim observado rebrote da parte aérea no final da avaliação. A redução na produção da biomassa, reflete os resultados encontrados para os níveis de controle (Figura 4).
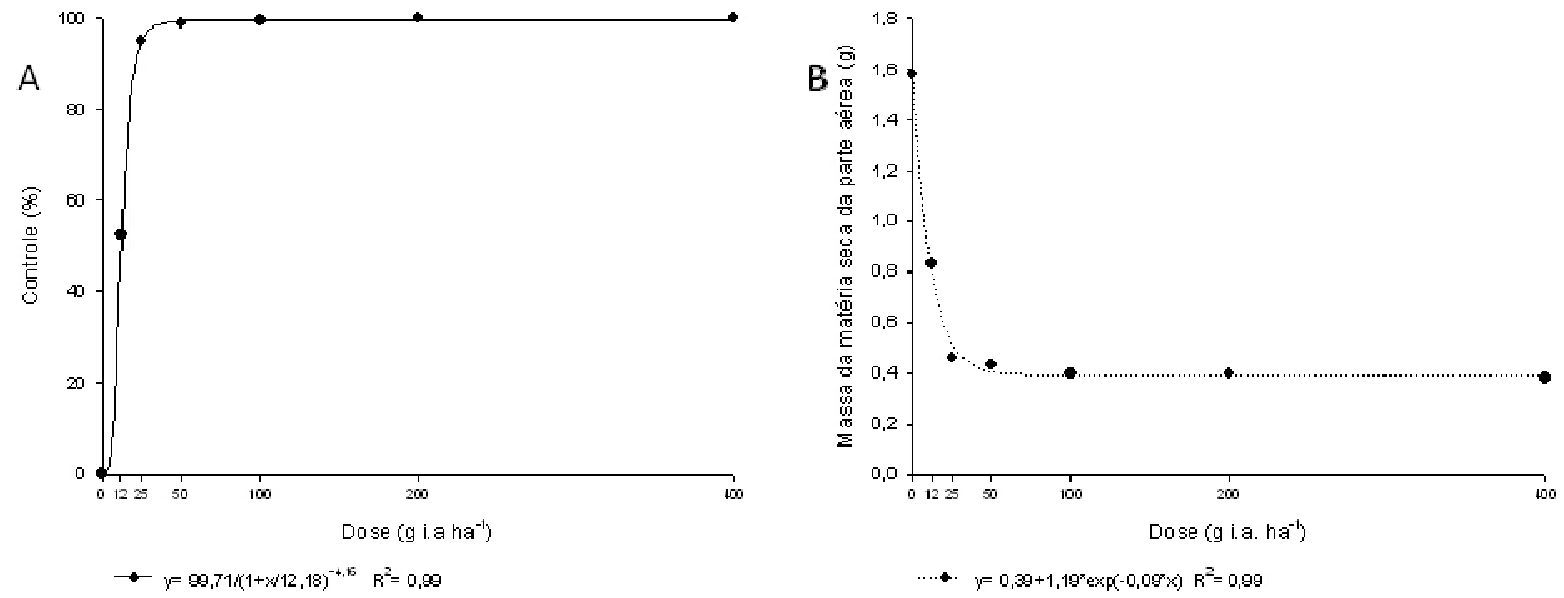

Figura 3. Porcentagem de controle (A) e massa de matéria seca da parte aérea de Merremia cissoides (B) aos 28 dias após aplicação do herbicida saflufenacil.
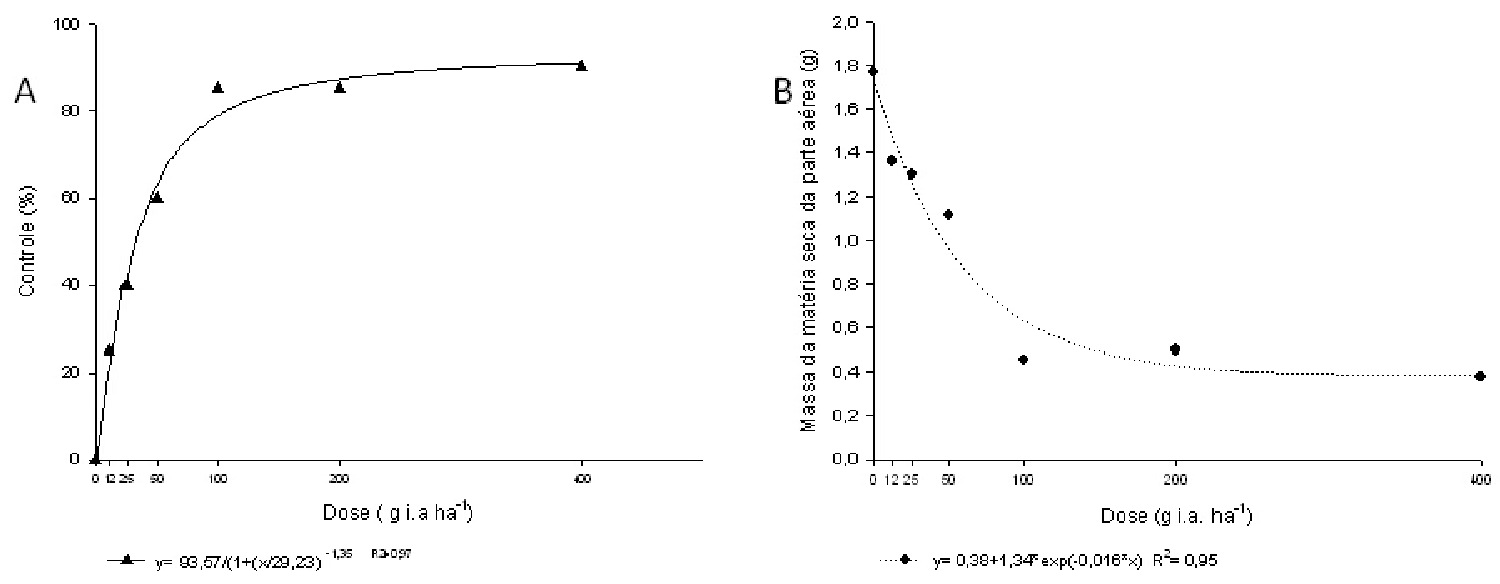

Figura 4. Porcentagem de controle (A) e massa de matéria seca da parte aérea de Lufta aegyptiana (B) aos 28 dias após aplicação do herbicida saflufenacil. 


\section{Conclusão}

Os resultados obtidos indicam que o herbicida saflufenacil controla de maneira satisfatória, a partir da metade da dose comercial (50 g i.a. ha ${ }^{-1}$, as espécies $M$. cissoides, $M$. aterrima e $R$. communis. A espécie $L$ aegyptiana apresenta maior tolerância à dose comercial de saflufenacil, sendo controlada apenas a partir de $100 \mathrm{~g}$ i.a. $\mathrm{ha}^{-1}$.

\section{Referências}

ASOCIATION LATINOAMERICANA DE MALEZAS. Recomendaciones sobre unificación de los sistemas de evaluación em ensayos de control de malezas. ALAM, Bogotá, v.1, p.3538, 1974.

BENINCASA, M.M.P. Análise de crescimento de plantas: Noções básicas. Jaboticabal: FUNEP, 2003. $42 \mathrm{p}$.

BURLE, M.L. et al. Caracterização das espécies de adubos verdes. In: Cerrado: adubação verde. Planaltina: Embrapa Cerrado, p.71-142, 2006.

CORREIA, N.M.; KRONKA JR., B. Controle químico de plantas dos gêneros Ipomoea e Merremia em cana-soca. Planta Daninha, v.28, n.esp, p. 1143-1152, 2010.

KISSMANN, K. G; GROTH, D. Plantas infestantes e nocivas. 2.ed. São Paulo: BASF, 1999. Tomo II. 978p.

KUVA, M.A. et al. Períodos de interferência das plantas daninhas na cultura da cana-de-açúcar: II - capim-braquiária (Brachiaria decumbens). Planta Daninha, v.19, n.3, p.323-330, 2001.

GRAVENA, R. et al. Controle de plantas daninhas através da palha de cana-de-açúcar associada à mistura dos herbicidas trifloxysulfuron-sodium + ametrina. Planta Daninha, v. 22, n. 3, p. 419-427, 2004.
LORENZI, H. Plantas daninhas e seu controle na cultura da cana-de-açúcar. In: SEMINÁRIO DE TECNOLOGIA AGRONÔMICA, 4, 1988, Piracicaba. Anais...São Paulo: COOPERSUCAR, 1988. p.281-301.

MARTINS, D. et al. Emergência em campo de dicotiledôneas infestantes em solo coberto com palha de cana-de-açúcar. Planta Daninha, v.17, n.1, p.151-161, 1999.

MEDEIROS, D. Efeito da palha de cana-deaçúcar sobre o manejo de plantas daninhas e dinâmica do banco de sementes. 2001. 125f. Dissertação (Mestrado em Produção Vegetal) Escola Superior de Agricultura Luiz de Queiroz, Piracicaba, 2001.

MONQUERO, P.A. et al. Mapas de infestação de plantas daninhas em diferentes sistemas de colheita da cana-de-açúcar. Planta Daninha, v.26, n.1, p.47-55, 2008.

MONQUERO, P. A. et al. Monitoramento do banco de sementes de plantas daninhas em áreas com cana-de-açúcar colhida mecanicamente. Planta Daninha, v.29, n.1, p.107-119, 2011.

PITELLI, R.A. Interferência de plantas daninhas em culturas agrícolas. Informe Agropecuário, v.11, n.129, p.16-27, 1985.

PROCÓPIO, S. O. et al. Manejo de plantas daninhas na cultura da cana-de-açúcar. Viçosa: UFV, 2003. 150 p.

QUEIROZ, U.C. de. Fitotoxicidade e seletividade do herbicida trifloxysulfuron sodium na mamoeira cultivar BRS Nordestina. 2007. 53f. Dissertação (Mestrado em agronomia). Universidade Federal da Paraíba, 2007.

SILVA, G. B. F. et al. Tolerância de espécies de mucuna aos herbicidas utilizados na cultura da cana-de-açúcar. In: CONGRESSO BRASILEIRO DA CIÊNCIA DAS PLANTAS DANINHAS. 27., 2010, Ribeirão Preto. Anais... p.1650-1653. 
TRIVELIN, P.C.O. et al. Utilização por soqueira de cana-de-açúcar de safra do nitrogênio da aquamônia-15N e uréia-15N aplicado ao solo em complemento a vinhaça. Pesquisa Agropecuária Brasileira, v.31, n.1, p.89-99, 1996.

VELINI, E.D.; NEGRISOLI, E. Controle de plantas daninhas em cana crua. In: CONGRESSO BRASILEIRO DA CIÊNCIA DAS PLANTAS DANINHAS, 22., 2000, Foz do Iguaçu. Palestras...

Foz do Iguaçu: 2000. p. 148-164. 